\title{
Coffee Consumption and Lung Cancer Risk: A Prospective Cohort Study in Khon Kaen Thailand
}

\author{
Wongklang Kudwongsa ${ }^{1,2}$, Supannee Promthet ${ }^{2}$, Kritika Suwanrungruang ${ }^{2,3}$, \\ Anakapong Phunmanee ${ }^{4}$, Patravoot Vatanasapt ${ }^{2,3,5 *}$
}

\begin{abstract}
Background: Lung cancer is a major cause of cancer death worldwide. The incidence of lung cancer in Thailand increasing, but risk factors are rarely reported. Objective: To investigate the effect of coffee consumption on lung cancer in Thai population. Methods: Between 1990 and 2001, lifestyle and demographic data were collected from 24,528 participants in the Khon Kaen Cohort Study (KKCS), who were followed through 2016, by linking to the Khon Kaen Population-based Cancer Registry. A total of 12,668 eligible participants $(68.8 \%$ females, mean age 51.0 years at baseline) having complete datasets (239,488 person-years of follow up with 138 incident cases of lung cancer observed) were analyzed using a multi-variable adjusted Cox proportional hazard models. Results: Coffee consumption was associated with reduced risk for lung cancer (adj. HR $=0.54 ; 95 \% \mathrm{CI}: 0.35-0.84$ ) after adjusting for age and gender. Cigarette smoking (adj. HR $=2.76 ; 95 \% \mathrm{CI}: 1.32-5.78)$ and family history of cancer (adj. HR $=1.65 ; 95 \% \mathrm{CI}: 1.10$ 2.48) were associated with higher risk. Conclusion: This study suggests coffee consumption may be a protective factor for lung cancer in among this cohort.
\end{abstract}

Keywords: Coffee- lung cancer- risk factors- cohort

Asian Pac J Cancer Prev, 21 (8), 2367-2371

\section{Introduction}

In 2018 , it is estimated that over 2 million new cases of lung cancer were diagnosed globally, while more than 1.7 million deaths occurred the highest among all cancers (Bray et al., 2018). In Thailand, lung cancer is the second leading cause of cancer-related deaths for both men and women, accounting for $4.8 \%$ and $3.3 \%$ of total deaths, respectively The incidence of lung cancer is highest in the northern region of the country (Wirasorn et al., 2014, 2016; Rankantha et al., 2018; Virani et al., 2017). The average annual percent change (AAPC) from 2000 to 2012 was $3 \%$, but is expected to show decline from 2012 to 2025 (Virani et al., 2017). A well-known risk factor for lung cancer is tobacco smoking (Li et al., 2017). A pooled analysis of Asian cohorts showed tobacco smoking is the strongest risk factor for lung cancer, increasing risk 3- to 4-fold (Zheng et al., 2014). Studies of alcohol drinking, however, have shown limited evidence for smoking-adjusted association with lung cancer risk, with most elevated odds ratios found in hospital-based case-control (Álvarez-Avellón et al., 2017; García Lavandeira et al., 2018).
Coffee consumption has been studied for its association with lung cancer risk. Generally, coffee consumption has not been shown to be significantly associated with lung cancer risk, but it has been shown to be a risk factor for increased risk among some sub-populations (Xie et al., 2016; Galarraga and Boffetta, 2016; Tang et al., 2010; Narita et al.,2018). Coffee consumption is highly associated with smoking (Guertin et al., 2016). The case-control studies in Thailand reported that chronic exposure to radon and cigarettes smoking increased risk of lung cancer (Pisani et al., 2006; Autsavapromporn et al., 2018). Until presently, no cohort study addressing risk factors of lung cancer in Thai population. Likewise, conflicting evidence was found for the effects of coffee consumption on lung cancer. The effect of coffee has also not been studied. Thus, the aim of this study was to investigate the effects of coffee consumption on lung cancer in Thai population.

\section{Materials and Methods}

Study design and cancer follow-up

A prospective cohort was conducted using the data

${ }^{1}$ Doctor of Philosophy Program in Epidemiology and Biostatistics, Faculty of Public Health, Khon Kaen University, Khon Kaen, Thailand. ${ }^{2}$ ASEAN Cancer Epidemiology and Prevention Research Group, Khon Kaen, Thailand. ${ }^{3}$ Cancer Registry Unit, Faculty of Medicine, Khon Kaen University, Khon Kaen, Thailand. ${ }^{4}$ Division of Pulmonology and Critical Care Medicine, Department of Medicine, Faculty of Medicine, Khon Kaen University, Khon Kaen, Thailand. ${ }^{5}$ Department of Otorhinolaryngology, Faculty of Medicine, Khon Kaen University, Khon Kaen, Thailand.*For Correspondence: patvat@kku.ac.th 
from Khon Kaen Cohort Study (KKCS). The study subjects were residents at Khon Kaen Province enrolled between 1990 and 2001. The inclusion criteria at enrollment were being aged $30-70$ years and having no previous diagnosis of cancer. The size of the recruited cohort was 24,528 participants, with 23,584 eligible participants (Figure 1). The exclusion criteria were incomplete data of citizen identification number and the variables to be analyzed. After removing missing data (10,916 participants, 44.5\%), the final analysis included 12,668 participants.

All subjects were followed-up until December 31, 2016 by linking with the population-based cancer registry of Khon Kaen Province to detect lung cancer occurrence using RECLINK-2 program. The vital status of all subjects was retrieved by data linkages with Thai national statistics database. The vital status of all subjects was retrieved by data linkages with the population statistics of the office of the Ministry of Interior using the personal identification number. The completeness of the Thai mortality data is reasonably high except the early infant death (Kijsanayotin et al., 2013). The lung cancer diagnosis was followed the International Classification of Disease for Oncology $3 \mathrm{rd}$. (ICD-O-3) (C34).

\section{Exposure assessment}

All subjects had physical examination at baseline and were interviewed by trained nurses using structured questionnaires. The variables of interests included general information, economic status, coffee consumption, cigarettes smoking, alcohol consumption and history of illness. The definition of coffee consumption is regular drinking of coffee.

\section{Statistical analysis}

To evaluate the relation between coffee consumption, other factors, and the risk of lung cancer, crude hazard ratios (CHR), adjusted hazard ratios (Adj.HR) with their 95 percent confidence intervals $(95 \% \mathrm{CI})$, and p-values were estimated using a multi-variable adjusted Cox proportional hazard models. Person-years in the cohort were calculated from baseline until cancer diagnosis, death, or loss to follow-up.

Prior to analysis, continuous variables were categorized into two groups Tests of homogeneity of subjects were done using Pearson's Chi-squared test. Bivariate crude analyses were used to identify factors associated with lung cancer for inclusion in the model ( $p$-value $\leq 0.25$ computed by Wald's test). Backward stepwise elimination method was used to remove non-significant factors $(\mathrm{p}<0.05)$. P-values were tested two-sided with values $<0.05$ considered significant. The assumption test of proportional hazard model was test for goodness of fit and test for fit model. All analyses were conducted in STATA program version 15.0 (copyright Faculty of Public Health, Khon Kaen University).

\section{Ethical considerations}

This research was approved by The Ethical Committee for Human Research of Khon Kaen University, Thailand (HE611216).

\section{Results}

Of 12,668 subjects, mean age 50.96 years, most of them were female $(68.8 \%)$, married $(85.2 \%)$, employed in agriculture, had a primary school education, lived in a nuclear household, and had a household income less than 10,000 THB/month (around 1,000 USD in 2020) (Table 1). The total follow-up was 239,488 person-years. Lung cancer was diagnosed in 138 cases ( 57.63 cases per 100,000 per year). The most common histology types were adenocarcinoma $(33.33 \%)$, followed by squamous cell carcinoma $(7.25 \%)$, large cell carcinoma $(5.07 \%)$, and small cell carcinoma $(0.72 \%)$, with the remaining cancers classified as unspecified malignant neoplasm (49.28\%).

Table 1. The General Characteristics of the Study Subjects in the Cohort

\begin{tabular}{|c|c|c|}
\hline Variables & $\mathrm{N}=12,668$ & $\%$ \\
\hline \multicolumn{3}{|l|}{ Sex } \\
\hline Male & 3,950 & 31.18 \\
\hline Female & 8,718 & 68.82 \\
\hline \multicolumn{3}{|l|}{ Age at recruitment } \\
\hline 30-39 Years old & 1,101 & 8.69 \\
\hline 40-49 Years old & 4,517 & 35.66 \\
\hline 50-59 Years old & 4,874 & 38.47 \\
\hline 60-70 Years old & 2,176 & 17.18 \\
\hline Mean (S.D.) & $50.96( \pm 8.08)$ & \\
\hline \multicolumn{3}{|l|}{ Marital status } \\
\hline Single & 260 & 2.05 \\
\hline Married & 10,808 & 85.32 \\
\hline Divorced or widowed & 1,600 & 12.63 \\
\hline \multicolumn{3}{|l|}{ Occupation } \\
\hline Agriculture & 10,928 & 86.27 \\
\hline Business owner & 497 & 3.92 \\
\hline Factory worker & 12 & 0.09 \\
\hline Laborer & 136 & 1.07 \\
\hline Government officer & 15 & 0.12 \\
\hline General employee & 116 & 0.92 \\
\hline Unemployed & 964 & 7.61 \\
\hline \multicolumn{3}{|l|}{ BMI $\left(\mathrm{kg} / \mathrm{m}^{2}\right)(\mathrm{n}=10,070)$} \\
\hline$<18.5$ & 626 & 6.22 \\
\hline $18.5-22.9$ & 3,800 & 37.74 \\
\hline $23-24.9$ & 1,966 & 19.52 \\
\hline$\geq 25$ & 3,678 & 36.52 \\
\hline \multicolumn{3}{|l|}{ Family size } \\
\hline Nuclear Family & 8,976 & 70.86 \\
\hline Extended family & 3,541 & 27.95 \\
\hline Big family & 151 & 1.19 \\
\hline \multicolumn{3}{|c|}{ Family income/month (Baht) } \\
\hline$<10,000$ & 12,216 & 96.43 \\
\hline $10,001-20,000$ & 319 & 2.52 \\
\hline $20,001-30,000$ & 90 & 0.71 \\
\hline$>30,000$ & 43 & 0.34 \\
\hline
\end{tabular}


Table 2. The Factors Associated with Lung Cancer

\begin{tabular}{|c|c|c|c|c|}
\hline Factors & $\begin{array}{c}\text { Number } \\
(\mathrm{N}=12,668)\end{array}$ & $\begin{array}{l}\text { Lung } \\
\text { cancer }\end{array}$ & $\begin{array}{l}\text { Crude HR } \\
(95 \% \mathrm{CI})\end{array}$ & $\begin{array}{c}P \\
\text { value }\end{array}$ \\
\hline Sex & & & & $<0.001$ \\
\hline Female & 8,718 & 54 & 1 & \\
\hline Male & 3,950 & 84 & $3.51(2.49-4.94)$ & \\
\hline Age at recruitment & & & & 0.002 \\
\hline 30-49 Years old & 5,618 & 46 & 1 & \\
\hline 50-70 Years old & 7,050 & 92 & $1.74(1.22-2.48)$ & \\
\hline BMI $\left(\mathrm{kg} / \mathrm{m}^{2}\right)$ & & & & 0.011 \\
\hline Normal weight & 3,800 & 60 & 1 & \\
\hline Low weight & 626 & 9 & $0.91(0.45-1.84)$ & \\
\hline $\begin{array}{l}\text { Overweight/ } \\
\text { Obese }\end{array}$ & 5,644 & 49 & $0.57(0.39-0.83)$ & \\
\hline Missing data & 2598 & & & \\
\hline \multicolumn{3}{|c|}{ History of family cancer } & & 0.027 \\
\hline No & 10,148 & 97 & 1 & \\
\hline Yes & 2,520 & 41 & $1.54(1.06-2.22)$ & \\
\hline Coffee Consumptio & & & & 0.161 \\
\hline No & 8,896 & 106 & 1 & \\
\hline Yes & 3,772 & 32 & $0.76(0.51-1.13)$ & \\
\hline Cigarette Smoking & & & & $<0.001$ \\
\hline No & 9,386 & 61 & 1 & \\
\hline Yes & 3,282 & 77 & $3.72(2.66-5.20)$ & \\
\hline Alcohol drinking & & & & 0.001 \\
\hline No & 6,719 & 56 & 1 & \\
\hline Yes & 5,949 & 82 & $1.75(1.25-2.46)$ & \\
\hline Betel nut chewing & & & & 0.738 \\
\hline No & 10,771 & 119 & 1 & \\
\hline Yes & 1,897 & 19 & $0.92(0.57-1.49)$ & \\
\hline
\end{tabular}

HR, Hazard ratio; 95\% CI, 95 percent confident interval; $P$-value from partial likelihood ratio

\section{Factors associated with lung cancer}

We found the risk of lung cancer was higher in males, cigarette smokers, those older at enrollment, and those with a family history of cancer (Table 2). Cigarette smoking demonstrated trends whereby increased exposure (e.g., less filtration or higher frequency was associated with increased risk of lung cancer (Table 2). No association was found for BMI or alcohol drinking. Coffee consumption was found to be a protective factor for Lung cancer (adj. HR =0.54; 95\% CI: 0.35-0.84).
The final multivariable model confirmed that coffee consumption was associated with reduced risk of lung cancer (Adj.HR=0.54; 95\% CI: 0.35-0.84). It also confirmed the risk of lung cancer from cigarette smoking (adj. $\mathrm{HR}=2.76 ; 95 \% \mathrm{CI}: 1.32-5.78$ ) and family history of cancer was likely to increase risk of lung cancer (adj. $\mathrm{HR}=1.65 ; 95 \%$ CI: 1.10-2.48) (Table 3).

\section{Discussion}

This study is the first cohort study on risk factors of lung cancer in Thailand. We found an inverse association between coffee consumption and lung cancer, with risk reduction of at least $16 \%$. Reduced risk of lung cancer has been identified among smokers who drink black tea (Mendilaharsu et al., 1998), and among smokers drinking decaffeinated coffee (Baker et al., 2005). Coffee consumption has also been associated with decreased risk of other cancers, such as bladder, breast, and colorectal cancers (Yu et al., 2011).

Coffee contains some biochemical compounds, polyphenols as the main bioactive, which has been found to be an antioxidant (Wierzejska, 2017), as well as catechins and flavonoids that found to be have chemoprotective effects such as promoting inhibiting oxidative stress, regulation of DNA repair, apoptosis, anti-inflammation, antiproliferative, oxidative damage, antiangiogenetic effects and antimetastatic effects (Baker et al., 2005; Bøhn et al., 2014). High intake of flavonoids, another compound found in coffee, also can reduce risk of lung cancer. Flavonoids intake about 20 $\mathrm{mg}$ /day decreased risk of lung cancer by $10 \%$ (Tang et al., 2009; Palmioli et al., 2017) Chlorogenic acid (CGA), an important biochemical active in of polyphenol found in coffee, affects inhibition of COX-2, MMP-2, and MMP-9 expression, which eventually reduced the risk of tumor enlargement and metastasis (Bułdak et al., 2018). CGA may also have anti-oxidative effects (Tajik et al., 2017).

This study used a large community-based prospective cohort and data linkage to the population-based cancer registry to ensure the temporality on its association. However, this study also has several limitations. First, only half of cancer cases were diagnosed with histopathological confirmation. But remaining cases were diagnosed with imaging which were verified for diagnosis of lung cancer

Table 3. Final Multivariate Model of Significant Factors Independently Associated with Lung Cancer

\begin{tabular}{|c|c|c|c|c|c|}
\hline Factors & Numbers & Lung cancer & Crude HR $(95 \% \mathrm{CI})$ & Adjusted HR* $(95 \% \mathrm{CI})$ & $P$-value** \\
\hline Coffee Consumption & & & & & 0.006 \\
\hline No & 8,896 & 106 & 1 & 1 & \\
\hline Yes & 3,772 & 32 & $0.76(0.51-1.13)$ & $0.54(0.35-0.84)$ & \\
\hline Cigarette Smoking & & & & & 0.007 \\
\hline No & 9,386 & 61 & 1 & 1 & \\
\hline Yes & 3,282 & 77 & $3.72(2.66-5.20)$ & $2.76(1.32-5.78)$ & \\
\hline History of family cancer & & & & & 0.014 \\
\hline No & 10,148 & 97 & 1 & 1 & \\
\hline Yes & 2,520 & 41 & $1.54(1.06-2.22)$ & $1.65(1.10-2.48)$ & \\
\hline
\end{tabular}

HR bases on backward elimination by cox proportion hazard regression; *HR, hazard ratio; adjusted for sex, age, and BMI; **p-value from Wald test. 


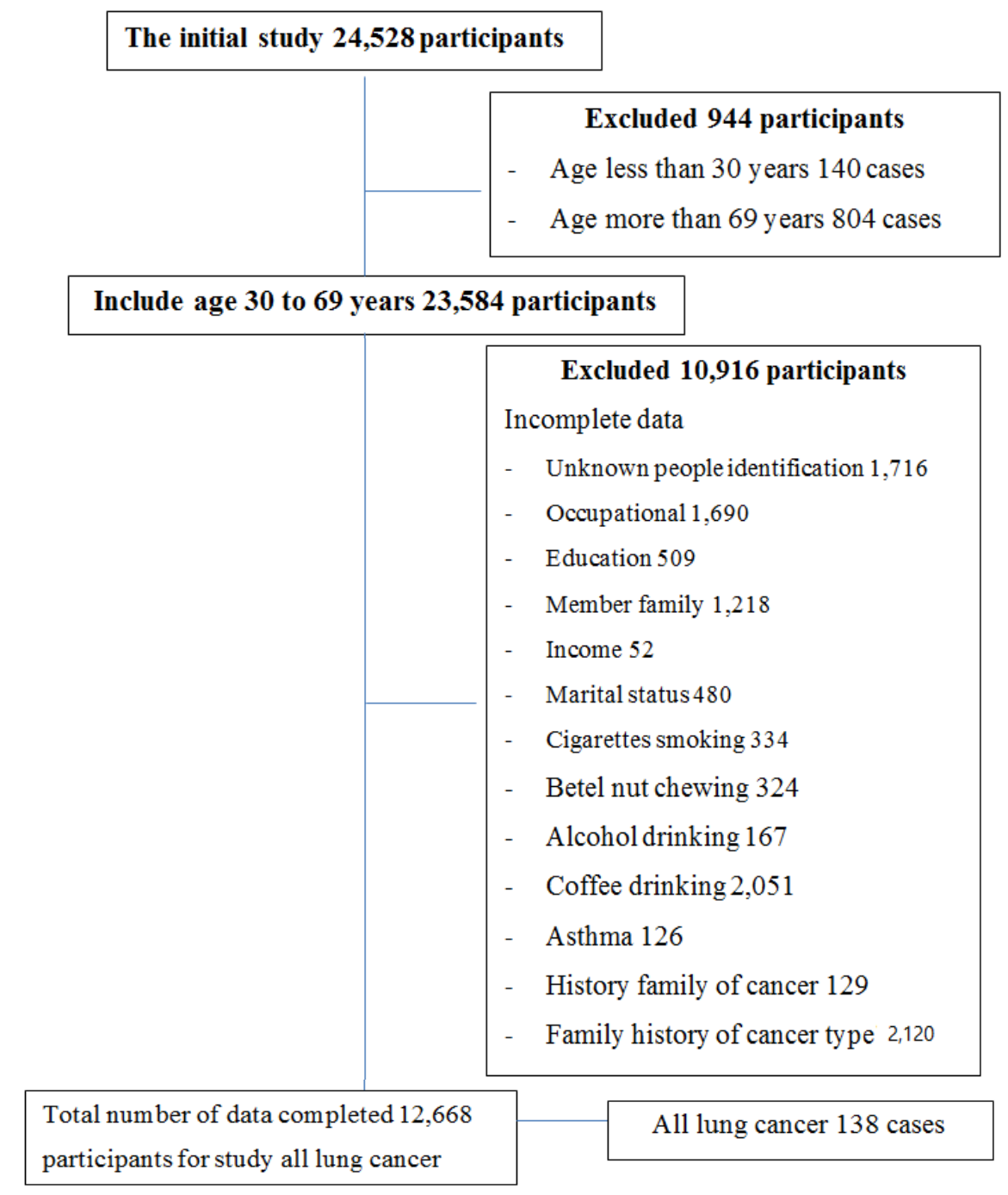

Figure 1. The Flowchart of Study

in the standard procedure for cancer registry. Second, the information on exposure relied on onetime interview at their enrollment without follow up data. Third, the data on type of coffee consumption (black coffee or mixed), and the amount of glass per day were not data collected at the beginning of projected. The future study on this topic should have more data collection detail. The recorded behaviors might have changed afterward causing non-differential misclassification. This would weaken association between those factors and lung cancer, but it would less likely to mislead their effects. The study also excluded a large proportion of eligible participants, which may have caused selection bias. As a result, the final analysis included demographics (e.g., 68.8\% female) that may not necessarily represent the community.

In conclusion, this study suggests that coffee consumption may be a protective factor for lung cancer among this cohort. Future study of coffee consumption with histological types of lung cancer in a larger sample sizes is needed. Further study on the effects of the biochemical compounds within coffee should also try to identify possibly mechanisms to explain protective effects on lung cancer.

\section{Acknowledgements}

The author would like to acknowledgement all of the staff at the Khon Kaen Cancer Registry Unit for their help and support on the cohort data and cancer registry data. Thank you also for the research funding from the ASEAN Cancer Epidemiology and Prevention Research Group, Khon Kaen University, Khon Kaen Province, Thailand.

Competing interests

None.

\section{References}

Álvarez-Avellón SM, Fernández-Somoano A, Navarrete-Muñoz EM, et al (2017). Effect of alcohol and its metabolites in lung cancer: CAPUA Study. Med Clin, 148, 531-8.

Autsavapromporn N, Klunklin P, Threeratana C, et al (2018). Short telomere length as a biomarker risk of lung cancer development induced by high Radon levels: A Pilot Study. Int J Environ Res Public Health, 15, e2152.

Baker JA, McCann SE, Reid ME, et al (2005). Associations between black tea and coffee consumption and risk of lung cancer among current and former smokers. Nutr Cancer, 52, 15-21. 
Bøhn SK, Blomhoff R, Paur I (2014). Coffee and cancer risk, epidemiological evidence, and molecular mechanisms. Mol Nutr Food Res, 58, 915-30.

Bray F, Ferlay J, Soerjomataram I, et al (2018). Global cancer statistics 2018: GLOBOCAN estimates of incidence and mortality worldwide for 36 cancers in 185 countries. $C A$ Cancer J Clin, 68, 394-424.

Bułdak RJ, Hejmo T, Osowski M, et al (2018). The Impact of coffee and its selected bioactive compounds on the development and progression of colorectal cancer in vivo and in vitro. Molecules, 23, 3309.

Dempsey S, Lyons S, Nolan A (2018). High Radon areas and lung cancer prevalence: Evidence from Ireland. J Environ Radioact, 182, 12-9.

Galarraga V, Boffetta P (2016). Coffee drinking and risk of lung cancer: A meta-analysis. Cancer Epidemiol Biomarkers Prev, 25, 951-7.

García Lavandeira JA, Ruano-Ravina A, Kelsey KT, et al (2018). Alcohol consumption and lung cancer risk in never smokers: A pooled analysis of case-control studies. Eur $J$ Public Health, 28, 521-7.

Guertin KA, Freedman ND, Loftfield E, et al (2016). Coffee consumption and incidence of lung cancer in the NIH-AARP Diet and Health Study. Int J Epidemiol, 45, 929-39.

Ito H, Matsuo K, Tanaka H, et al (2011). Nonfilter and filter cigarette consumption and the incidence of lung cancer by histological type in Japan and the United States: Analysis of 30-year data from population-based cancer registries. Int J Cancer, 128, 1918-28.

Jung KJ, Jeon C, Jee SH (2016). The effect of smoking on lung cancer: ethnic differences and the smoking paradox. Epidemiol Health, 38, e2016060.

Kijsanayotin B, Sumputtanon K, Ingun P (2013). Rapid Assessment of National Civil Registration and Vital Statistics Systems: A case study of Thailand. Bangkok: Health Systems Research Institute.

Li J, Yang F, Li X, et al (2017). Characteristics, survival, and risk factors of Chinese young lung cancer patients: The experience from two institutions. Oncotarget, 8, 89236-44.

Mendilaharsu M, De Stefani E, Deneo-Pellegrini H, Carzoglio JC, Ronco A (1998). Consumption of tea and coffee and the risk of lung cancer in cigarette-smoking men: A case-control study in Uruguay. Lung Cancer, 19, 101-7.

Narita S, Saito E, Sawada N, et al (2018). Coffee consumption and lung cancer risk: The Japan public health center-based prospective study. $J$ Epidemiol, 28, 207-13.

Ngamwong Y, Tangamornsuksan W, Lohitnavy O, et al (2015). Additive synergism between asbestos and smoking in lung cancer risk: A systematic review and meta-analysis. PLoS One, 10, e0135798.

Palmioli A, Ciaramelli C, Tisi R, et al (2017). Natural Compounds in cancer prevention: Effects of coffee extracts and their main polyphenolic component, 5-O-caffeoylquinic acid, on oncogenic ras proteins. Chem Asian J, 12, 2457-66.

Pisani P, Srivatanakul P, Randerson-Moor J, et al (2006). "GSTM1 and CYP1A1 Polymorphisms, Tobacco, Air Pollution, and Lung Cancer: A Study in Rural Thailand." Int J Environ Res Public Health, 15, 667-74.

Rankantha A, Chitapanarux I, Pongnikorn D, et al (2018). Risk patterns of lung cancer mortality in northern Thailand. $B M C$ Public Health, 18, 1138.

Sobue T, Yamamoto S, Hara M, et al (2002). Cigarette smoking and subsequent risk of lung cancer by histologic type in middle-aged Japanese men and women: the JPHC study. Int $J$ Cancer, 99, 245-51.

Tajik N, Tajik M, Mack I, Enck P (2017). The potential effects of chlorogenic acid, the main phenolic components in coffee, on health: A comprehensive review of the literature. Eur $J$ Nutr, 56, 2215-44.

Tang N, Wu Y, Ma J, Wang B, Yu R (2010). Coffee consumption and risk of lung cancer: A meta-analysis. Lung Cancer, 67, 17-22.

Tang NP, Zhou B, Wang B, Yu RB, Ma J (2009). Flavonoids intake and risk of lung cancer: A meta-analysis. Jpn J Clin Oncol, 39, 352-9.

Virani S, Bilheem S, Chansaard W, et al (2017). National and Subnational population-based incidence of cancer in Thailand: Assessing cancers with the highest burdens. Cancers (Basel), 9, E108.

Wierzejska R (2017). Coffee drinking and health - the current state of knowledge. whether the end of the doubts of patients is already coming?. Wiad Lek, 70, 850-4.

Wirasorn K, Suwanrungruang K, Sookprasert A, et al (2016). Hospital-based population of elderly cancer cases in Northeastern Thailand. Asian Pac J Cancer Prev, 17, 767-70.

Wirasorn K, Suwanrungruag K, Wiangnon S, Punjaruk W (2014). Numbers of new cases and trends of cancer 19932012: Srinagarind hospital-based population, Khon Kaen, North- East Thailand. Asian Pac J Cancer Prev, 15, 8423-7.

Xie Y, Qin J, Nan G, et al (2016). Coffee consumption and the risk of lung cancer: an updated meta-analysis of epidemiological studies. Eur J Clin Nutr, 70, 199-206.

Yu X, Bao Z, Zou J, Dong J (2011). Coffee consumption and risk of cancers: A meta-analysis of cohort studies. $B M C$ Cancer, 11, 96.

Zheng W, McLerran DF, Rolland BA, et al (2014). Burden of total and cause-specific mortality related to tobacco smoking among adults aged $\geq 45$ years in Asia: A pooled analysis of 21 cohorts. PLoS Med, 11, e1001631.

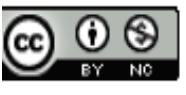

This work is licensed under a Creative Commons AttributionNon Commercial 4.0 International License. 